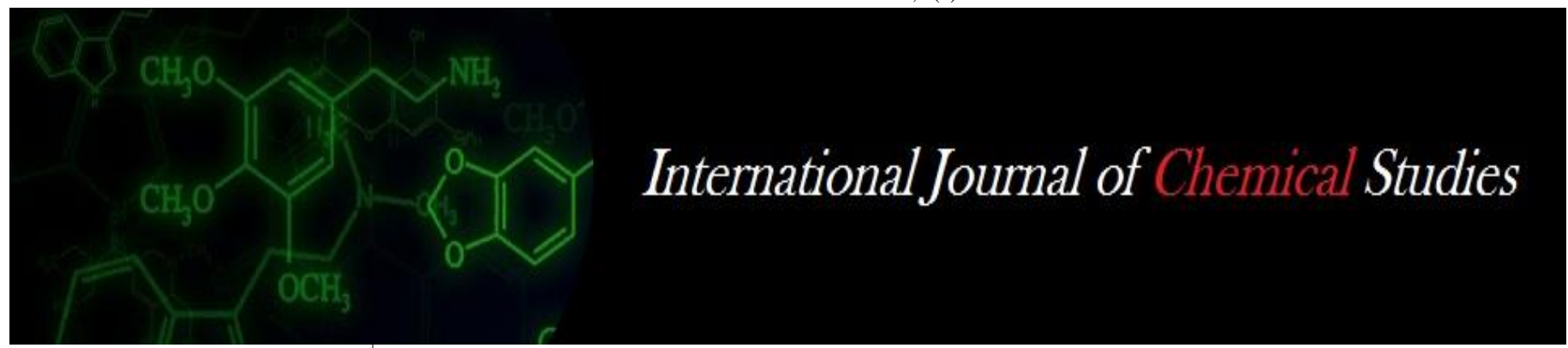

P-ISSN: 2349-8528

E-ISSN: 2321-4902

www.chemijournal.com

IJCS 2020; 8(3): 2954-2958

(C) 2020 IJCS

Received: 10-03-2020

Accepted: 12-04-2020

\section{Sonali Swagatika}

Department of Soil and Water

Conservation Engineering,

College of Agricultural

Engineering and Technology,

Centurion University of

Technology and Management,

Parlehmundi, Odisha, India

Prabhat Ranjan Khakha

Department of Soil and Water

Conservation Engineering,

College of Agricultural

Engineering and Technology,

Orissa University of Agriculture

and Technology, Odisha India

Saphalya sunder Sahoo

Department of Soil and Water

Conservation Engineering,

College of Agricultural

Engineering and Technology,

Centurion University of

Technology and Management,

Parlehmundi, Odisha India

\section{Anshuman Nayak}

Department of Soil and Water

Conservation Engineering,

College of Agricultural

Engineering and Technology,

Centurion University of

Technology and Management,

Parlehmundi, Odisha India

Corresponding Author: Sonali Swagatika

Department of Soil and Water

Conservation Engineering,

College of Agricultural

Engineering and Technology,

Centurion University of

Technology and Management,

Parlehmundi, Odisha, India

\section{A study on smart irrigation system on a watershed}

\author{
Sonali Swagatika, Prabhat Ranjan Khakha, Saphalya sunder Sahoo and \\ Anshuman Nayak
}

DOI: https://doi.org/10.22271/chemi.2020.v8.i3aq.9660

\begin{abstract}
Automatic irrigation system was carried out on a small area. The study was confined to Parlakhemundi area of Gajapati district situated in agro-climatic zone-5. The main focus of the study is to plan automatic irrigation, when the soil moisture level decreases to certain extent then only irrigation is provided and the other is to check the accuracy of the sensors compared to other instruments in our given plot. As irregular irrigation causes lot of wastage of water. So, in order to save water and time IOT has been used (PC based). There are various sensors like temperature, humidity, soil moisture sensors which senses the various parameters of the soil and based on soil moisture value land gets automatically irrigated by $\mathrm{ON} / \mathrm{OFF}$ of the motor. A comparison between the recordings i.e for soil moisture, recordings of both tensiometer and sensors are taken and the error between them is detected. Likewise for temperature and humidity both the recordings are compared and error is detected. Mulches i.e. straw, grass, saw dust and combination of saw dust and grass is taken into account.
\end{abstract}

Keywords: Mulch, internet of things, soil moisture sensor, temperature sensor, humidity sensor

\section{Introduction}

India's major source of income is from agriculture sector and $70 \%$ of farmers and general people depend on the agriculture. In India most of the irrigation systems are operated manually where there might be a chance of over irrigation. These outmoded techniques are replaced with semi-automated and automated techniques. Traditional techniques like ditch irrigation, terraced irrigation, drip irrigation, sprinkler system are available. (Kansara. K. et al., 2015) ${ }^{[5]}$ But we need to modify our methods we are using during irrigating our crops. We need to increase our food productivity with less water as the water scarcity is increasing day by day. In India, agriculture plays an important role for development in food production. Mostly agriculture depends on the monsoons. The average annual rainfall over India is computed to be $1170 \mathrm{~mm}$, which is much higher than the global average of $800 \mathrm{~mm}$. but this rainfall occurs at high intensity and short 'duration as a result most of the rain falling on the surface tends to flow fast, leaving a little scope for recharging the ground water. To fulfil the water requirement of the crop substantial irrigation is provided. At this point which Internet of Things (IOT) proves to be a milestone in the evolution of technology for irrigation.

IOT plays an important role in many fields, one of that is Agriculture by which it can feed billions of people on Earth in future. IOT helps the farmer to aware them about the field conditions. The can be aware about the soil temperature, ph level, humidity, amount of water needed. It can be used when the farmer is not around through sensors. Mainly it is used to optimize their crop.

Modern irrigation pumps are gradually being shifting from conventional switches to centralized control system, involving remote controlled switches. Presently, conventional pump switches located in different parts of the agriculture land makes it difficult for the user to go near them to operate and physically present on those areas. Even more it becomes more difficult for the elderly or physically handicapped people to do so. Remote controlled irrigation automation system provides a most modern solution with smart phones for those persons who want to do agriculture without physically present on that place. (Sangekar., S. et al., 2019) ${ }^{[8]}$ 
Smart /Automating farm or nursery irrigation permits farmers to use the correct quantity of water at the correct time, regardless of the provision of labour to show valves on and off. Additionally, farmer's mistreatment automation instrumentation is able to scale back runoff from over watering saturated soil, avoid irrigating at the incorrect time of day, which will improve crop performance by making certain adequate water and nutrients once required. Those valves are also simply automated by mistreatment controllers. Proper scheduling is critical for effective water management in crop production, particularly in water scarcity area. The amount of water application, irrigation frequency, and water use are particularly important. To improve the water efficiency proper irrigation scheduling is necessary. For this smart irrigation is done.

\section{Materials and Methods}

Odisha state consists of 30 district with varied geographical area. It has been divided into 10 agro-climatic zones. The various district falls under different zone are shown in the [Fig-1]. The present study was confined to Parlakhemundi area of Gajapati district situated in agro-climatic zone-5. The area is inside the Centurion University of technology and management campus at latitude $\mathrm{N} 18^{\circ} 48^{\prime} 33.48108^{\prime \prime}$ and longitude E $84^{\circ} 8^{\prime} 37.22424^{\prime \prime}$. It is situated beside the NH326A within the boundary of CUTM, having dimension of $15.0 \mathrm{X}$ $6.5 \mathrm{~m}$ i.e. area of $97.5 \mathrm{~m} 2$

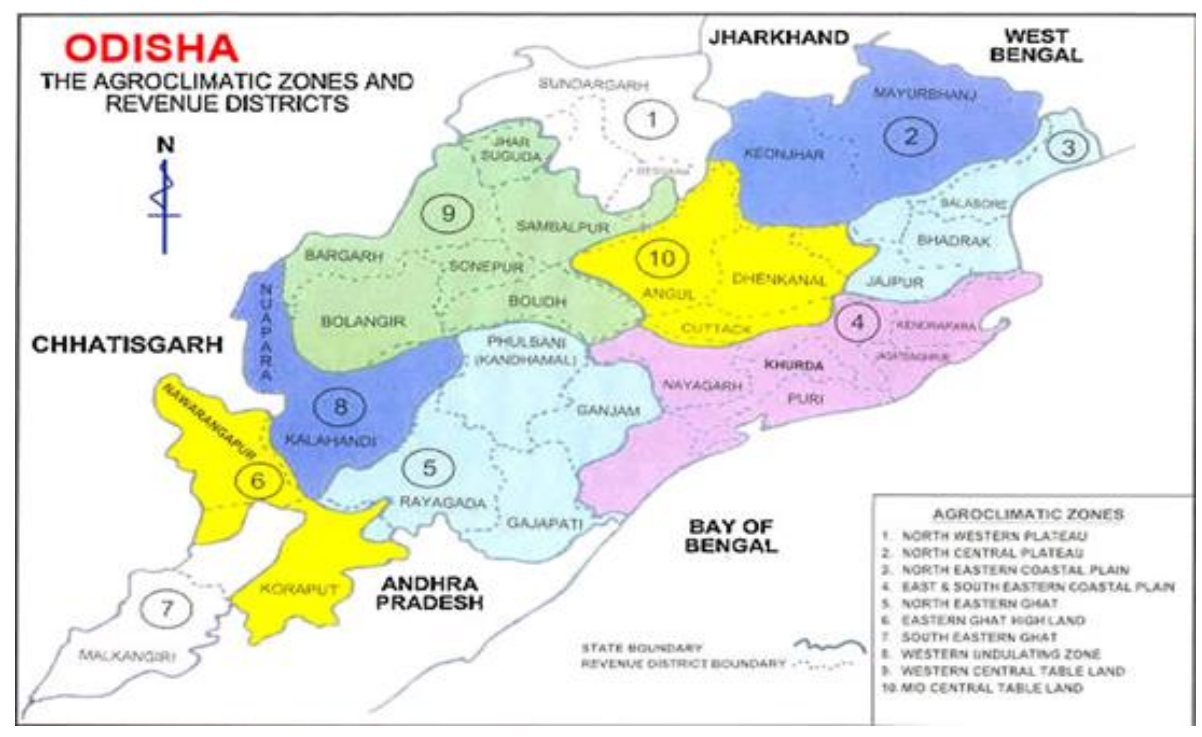

Fig 1: Agro-Climatic Zone of Odisha

\section{Smart Irrigation}

This prototype monitors the amount of soil moisture and temperature and humidity. A predetermined range of soil moisture, temperature and humidity is set, based on the crops. The probes are inserted into the soil where the system is connected. As soon as the sensor senses dry soil it automatically turns $\mathrm{ON}$ the motor which is connected to a battery and when enough water is available in the soil surface the sensor turns OFF the motor. The sensor is connected to a PC where the recordings are depicted. It consists of Arduino mega 2560 which is the brain of the system both moisture and temperature-humidity sensors are connected to the input pins of the controller. The LCD display/PC is connected to the output pins. A proposed smart irrigation system is depicted in Fig.2 and Fig.3.

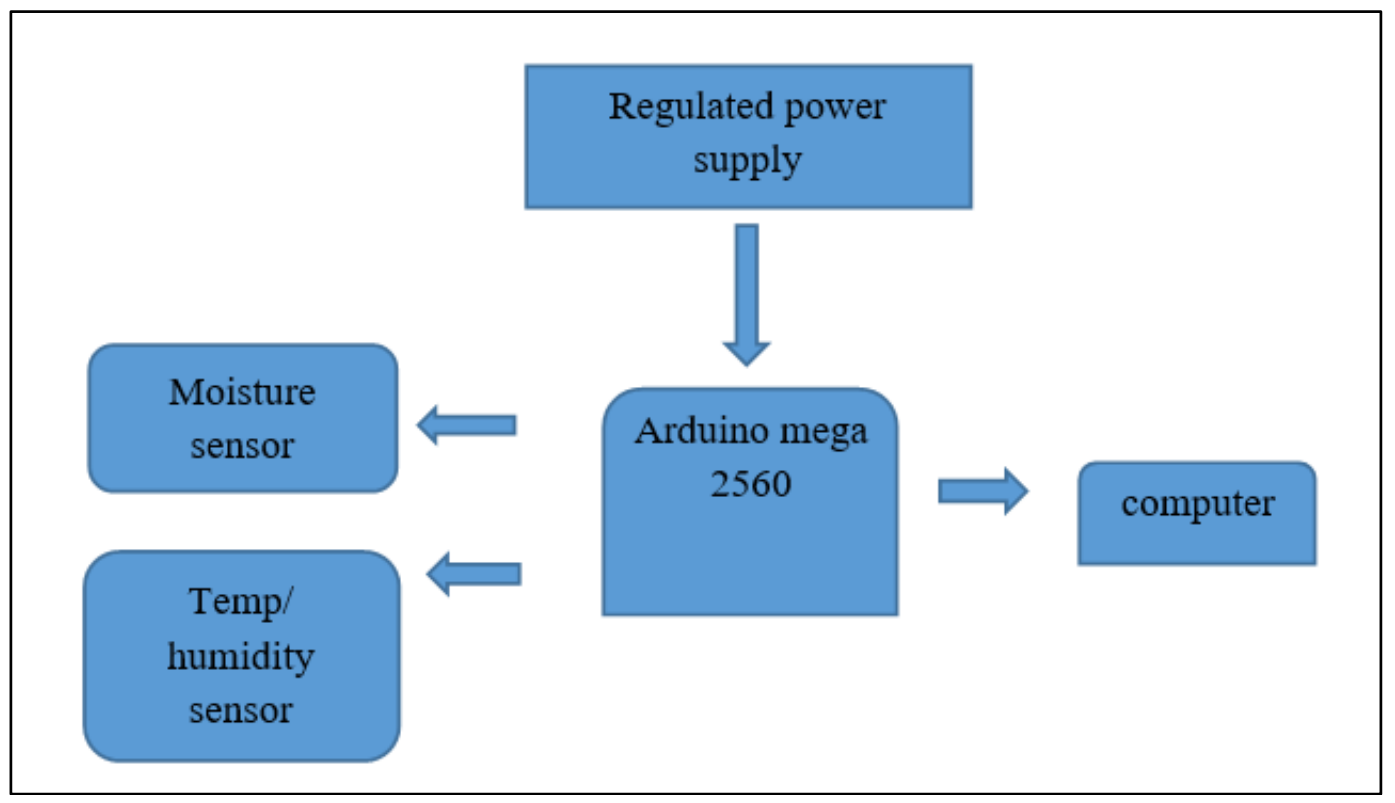

Fig 2: Block diagram of smart irrigation system 


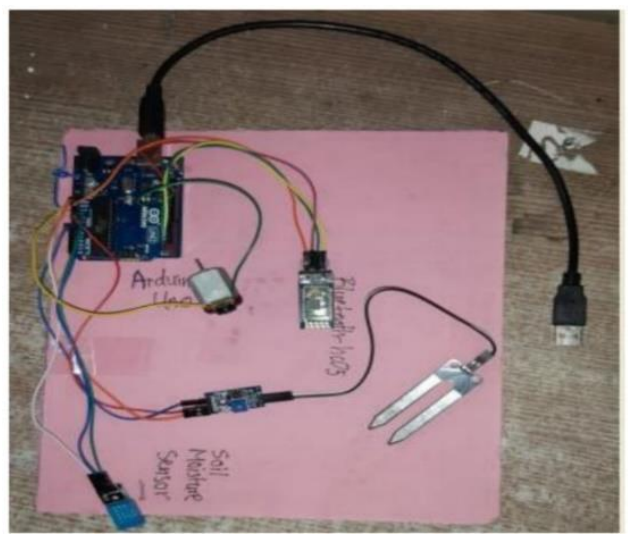

Fig 3: Proposed system of smart irrigation using IOT

\section{Components}

\subsection{Soil moisture sensor}

Soil moisture sensor measures the volumetric water content in soil. When the soil having water shortage, the module output is at high level, else output is at low level. The sensor has mainly two probes to sense the moisture content in the soil. In this, the sensor is connected with a PC and the motor is connected to a battery. The probes of the sensor are dipped into the soil. When the sensor sense dry soil the motor is automatically turns $\mathrm{ON}$ and water supply is started. As soon as the sensor gets moist it turns OFF the motor. The ON/OFF can be seen in the display. The soil moisture sensor is used to measures the loss of moisture over time due to evaporation and plant uptake. The soil moisture sensor is shown in Fig.3. and temperature sensor is shown in Fig.4.

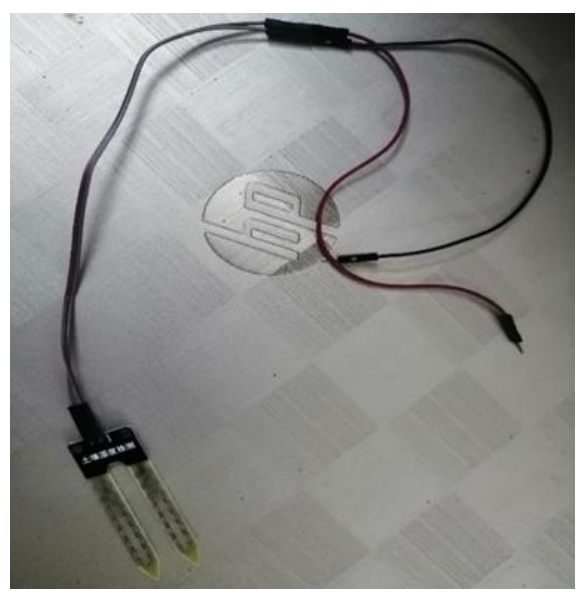

Fig 3: Soil moisture sensor

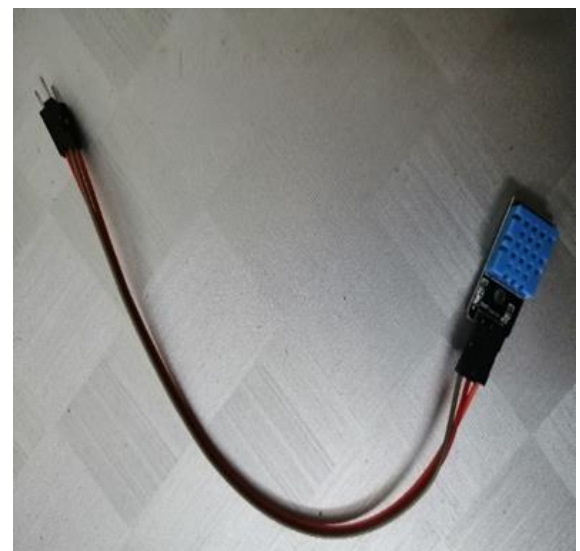

Fig 4: Temperature and humidity sensor

\subsection{Temperature and Humidity sensor}

This sensor is used to measure temperature and humidity with the Arduino board. Here DHT 11 sensor is being used as shown in Fig.4. The sampling rate of which is $1 \mathrm{~Hz}$ or one reading for every second. It has comparatively smaller body size. The voltage in which it is operated is from 3-5Volts, while the maximum current used when measuring is $2.5 \mathrm{~mA}$. Basically there are two electrodes with moisture holding substrate between them. As the humidity fluctuates, the conductivity of the substrate also changes, this change gives us the humidity. And for temperature measurement a thermistor is provided, which changes its resistance with the change in temperature. The resistance decreases with the increase of the temperature.

\subsection{Arduino mega 2560}

Arduinos processor basically uses the Harvard architecture where the program code and program data have separate memory. It consists of two memories- program memory and the data memory. The code is stored in the flash program memory, whereas the data stored in the data memory. It has 54 digital input/output pins, 16 analog inputs, 4 UARTs, 16 $\mathrm{MHz}$ crystal oscillator, a USB connection, a power jack, an ICSP header, and a reset button.It has everything to get connected. A computer with a USB cable or with a AC-to$\mathrm{DC}$ adapter or a battery to get it started. The operating voltage is about $5 \mathrm{~V}$, input voltage that is recommended is about 7 12V. It is shown in Fig.5.

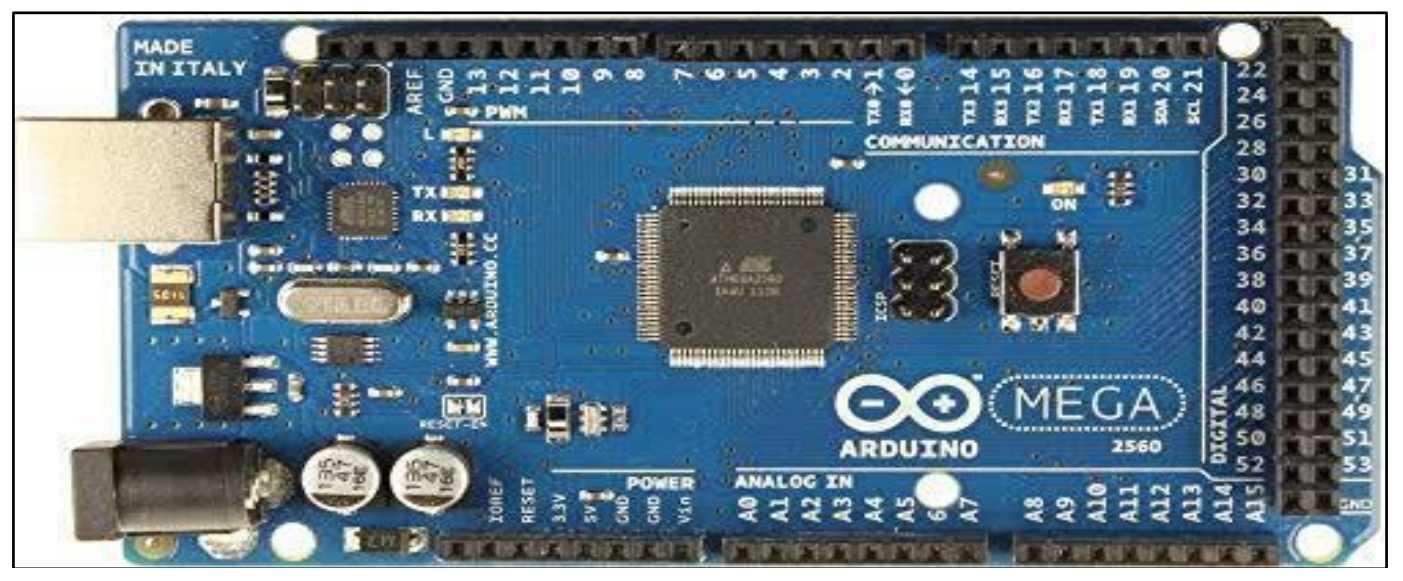

Fig 5: Arduino Mega 2560 


\subsection{Methods}

In this study we have taken different types of mulches. The mulches used are straw, grass, saw dust and mixture of straw and grass. We have recorded all the parameters i.e. temperature, humidity, soil moisture using sensors and other equipment to compare the accuracy of the sensor in our given plot. After the unit is properly assembled, the USB cables are connected to a laptop/LCD display for the results. After calibration of these sensors these readings are taken. Standard deviation with other widely used instruments was also taken into account.

\section{Results and Discussion}

\subsection{Measurement of soil moisture}

For the soil moisture measurement tensiometer is taken. The soil moisture is measured in both tensiometer and by using sensors. In the mulch which is having straw the reading of tensiometer and sensor readings are depicted to be $54 \%$ and $60 \%$ respectively giving an error of $11 \%$. Whereas for grass mulch the reading of tensiometer and sensor readings are depicted to be $55 \%$ and $64 \%$ respectively giving an error of $16 \%$. Likewise for sawdust the reading of tensiometer and sensor readings are depicted to be $58 \%$ and $65 \%$ respectively giving an error of $12 \%$ and for combination of straw and grass mulch the reading of tensiometer and sensor readings are depicted to be $58 \%$ and $62 \%$ respectively giving an error of $6.8 \%$.

Table 1: Soil moisture reading

\begin{tabular}{|c|c|c|c|}
\hline Types of mulches & Tensiometer reading (\%) & Soil moisture reading (\%) & Error (\%) \\
\hline Straw & 54 & 60 & 11 \\
\hline Grass & 55 & 64 & 16 \\
\hline Saw dust & 58 & 65 & 12 \\
\hline Mixture of straw and grass & 58 & 62 & 6.8 \\
\hline
\end{tabular}

\subsection{Measurement of Humidity and temperature}

For the humidity measurement hygrometer is taken. The humidity is measured in both hygrometer and by using sensors. In the mulch which is having straw the reading of hygrometer and sensor readings are depicted to be $43 \%$ and $38 \%$ respectively giving an error of $11 \%$. Whereas for grass mulch the reading of hygrometer and sensor readings are depicted to be $50 \%$ and $45 \%$ respectively giving an error of $10 \%$. Likewise for sawdust the reading of hygrometer and sensor readings are depicted to be $44 \%$ and $36 \%$ respectively giving an error of $18 \%$ and for combination of straw and grass mulch the reading of hygrometer and sensor readings are depicted to be $48 \%$ and $39 \%$ respectively giving an error of $18 \%$.
For the temperature measurement pyrometer is taken. The temperature is measured in both pyrometer and by using sensors. In the mulch which is having straw the reading of pyrometer and sensor readings are depicted to be $35.4 \%$ and $34.8 \%$ respectively giving an error of $1.69 \%$. Whereas for grass mulch the reading of pyrometer and sensor readings are depicted to be $34.5 \%$ and $34 \%$ respectively giving an error of $1.44 \%$. Likewise for sawdust the reading of pyrometer and sensor readings are depicted to be $36 \%$ and $35 \%$ respectively giving an error of $2.77 \%$ and for combination of straw and grass mulch the reading of pyrometer and sensor readings are depicted to be $37 \%$ and $36.4 \%$ respectively giving an error of $1.62 \%$.

Table 2: Humidity and temperature reading

\begin{tabular}{|c|c|c|c|c|c|c|}
\hline Types of mulches & $\begin{array}{c}\text { Humidity (\%) } \\
\text { (hygrometer) }\end{array}$ & $\begin{array}{c}\text { Temp }\left({ }^{\mathbf{0}} \mathbf{C}\right) \\
\text { pyrometer }\end{array}$ & $\begin{array}{c}\text { Humidity } \\
(\text { sensor) }\end{array}$ & $\begin{array}{c}\text { Temp }\left({ }^{\mathbf{}} \mathbf{C}\right) \\
(\text { sensor) }\end{array}$ & Error\% of humidity & Error\% of temp \\
\hline Straw & 43 & 35.4 & 38 & 34.8 & 11 & 1.69 \\
\hline Grass & 50 & 34.5 & 45 & 34 & 10 & 1.44 \\
\hline Saw dust & 44 & 36 & 36 & 35 & 18 & 2.77 \\
\hline Mixture of straw and grass & 48 & 37 & 39 & 36.4 & 18 & 1.62 \\
\hline
\end{tabular}

\section{Conclusion}

From the study conducted at CUTM, parlekhmundi campus, it is observed that through proper irrigation schedule we can increase the crop productivity and can also control the over irrigation which could be harmful for the crop. It is also observed that when there is an error of $6-16 \%$ in soil moisture reading, $10-18 \%$ error in case of humidity and up to $1-3 \%$ error in case of temperature when measured using sensors and their respective instruments.

\section{Suggestions for future work}

We can interface LCD screen in order to display amount of water utilized by the plant, duration of the time for which the motor is operating. We can also focus to regulate it by Android IOS and Microsoft devices so that it will be very easy for the farmers to use it.

\section{References}

1. Amalraj JJ, Banumathi S, Jereena John J. A study on smart irrigation systems for agriculture using Iot. Int. J of Scientific \& Technology. 2019; 8(12):1935-1938.

2. Ashwini BV. A Study on Smart Irrigation System Using IoT for Surveillance of Crop-Field. International Journal of Engineering \& Technology. 2018; 7(4, 5):370-373

3. Chetan R, Damodharan G, Elumalai K, Eswaran C, Manjula C. Smart irrigation system for Agricultural Field Using Labview and IOT. Int. J. of Innovation research in Science, Engineering \& Technology. 2018; 7(1):143-146.

4. Hemalat R, Deepika G, Dhanalakhmi D, Dharanipriya K, Divya M. Internet of Things (IoT) Based Smart Irrigation. Int. $\mathrm{J}$ of Advanced Research in Biology Engineering Science and Technology. 2016; 2(2):128131. 
5. Kansara k, Zaveri V, Shah S, Delwadkar S, Jani K. Sensor based Automated Irrigation System with IOT. International Journal of Computer Science and Information Technologies, 6(6), 5331-5333.

6. Kumar GR, Gopal TV, Sridhar V, Nagendra G. Smart irrigation System. Int. J. of pure \& Applied Mathematics, 119(15), 1155-1167.

7. Naik CG, Krishna A, Srinitha S. Shenoy and N. Naik. Integrated farming System using IOT Bluetooth. Int. Research Journal of Engineering \& Technology, 7(4), 6459-6464.

8. Sangekar S, Juneja P, Dhanwade A, Pathak M, Kalbande $\mathrm{D}$, Bhakta D et al. Smart village using IOT. International Research Journal of Engineering and Technology, 6(1), 1721-1724.

9. Singla B, Mishra S, Singh A, Yadav S. A study on smart irrigation using IoT. Int. J of Advance Research, Ideas and Innovations in Technology. 2019; 5(2):1416-1418. 